\title{
Interactive inhibitory effects of formoterol and montelukast on activated human
} neutrophils

\author{
C.M. Gravett*, A.J. Theron*, H.C. Steel*, G.R. Tintinger*, R. Cockeran*, \\ C. Feldman" ${ }^{\#}$ and R. Anderson*
}

ABSTRACT: The research question addressed in the current study was: do formoterol (1 and $10 \mathrm{nM})$ and montelukast $(2 \mu \mathrm{M})$ possess interactive inhibitory effects on activated human neutrophils, particularly in relation to alterations in cyclic AMP and cytosolic $\mathrm{Ca}^{2+}$ fluxes?

Isolated human blood neutrophils were activated with the chemoattractant $\mathrm{N}$-formyl-Lmethionyl-L-leucyl-L-phenylalanine (fMLP) $(1 \mu \mathrm{M})$ in combination with cytochalasin B (CB; $3 \mu \mathrm{M})$. Fura-2-acetoxymethyl ester-based spectrofluorimetry, lucigenin-enhanced chemiluminescence, colorimetric and flow cytometric procedures were used to measure cytosolic $\mathrm{Ca}^{2+}$ fluxes, production of superoxide, elastase release and beta-2 integrin (CR3) expression, respectively, while cyclic AMP and leukotriene $(\mathrm{LT}) \mathrm{B}_{4}$ were assayed using competitive binding ELISA procedures.

Activation of the cells with $\mathrm{AMLP} / \mathrm{CB}$ resulted in abrupt and sustained increases in cytosolic $\mathrm{Ca}^{2+}$, as well as release of elastase and production of superoxide and $\mathrm{LTB}_{4}$, and expression of CR3, all of which were attenuated by formoterol and montelukast individually, and especially by the combination of these agents. These anti-inflammatory effects of each agent, as well as the combination, were associated with significant increases in cyclic AMP.

The findings of the current study may explain the efficacy of montelukast and formoterol when used in combination with inhaled corticosteroids in the treatment of severe asthma, possibly by controlling neutrophil-driven inflammation of the airways.

KEYWORDS: Calcium, cyclic AMP, elastase, leukotriene $\mathbf{B}_{\mathbf{4}}$, neutrophils, superoxide

A nti-inflammatory chemotherapy, most commonly inhaled corticosteroids, is the cornerstone of the pharmacotherapy of bronchial asthma [1]. In patients not controlled on corticosteroids alone, the guideline recommendation is that an additional controller therapy should be added, either a long-acting $\beta_{2^{-}}$ adrenoreceptor agonist (LABA) or a cysteinyl leukotriene receptor (cysLTR) antagonist [2]. In patients who are still not adequately controlled, a combination of controller medications is added to the inhaled corticosteroids [2]. With the possible exception of the effects of corticosteroids on $\beta_{2^{-}}$ receptor expression and function [3-5], the clinical benefit of this triad of agents is thought to result from the collective effects of their distinct mechanisms of therapeutic activity, as opposed to meaningful, beneficial interactions between them. Corticosteroids possess broad spectrum antiinflammatory activity, while LABAs and montelukast function primarily as bronchodilators and through antagonism of cysLTRs, respectively [6, 7].
There is, however, evidence that LABAs and montelukast, in addition to their conventional therapeutic activities, possess anti-inflammatory properties [4, 8-10]. If operative in vivo, these may complement the anti-inflammatory actions of corticosteroids in controlling severe asthma, especially those types of asthma in which the seemingly corticosteroid-resistant neutrophil [6] is the dominant type of inflammatory cell [11].

The pro-inflammatory activities of neutrophils, as well as other types of immune and inflammatory cells, are suppressed by pharmacological agents that elevate intracellular cyclic AMP (cAMP) [12] Because these cells possess $\beta_{2}$-adrenoreceptors, they are amenable to the anti-inflammatory actions of $\beta_{2}$-agonists, including the selective, long-acting agent, formoterol [4, 8]. Montelukast has also been reported to increase intracellular cAMP by a mechanism distinct from antagonism of cysLTRs, which involves nonspecific inhibition of cyclic nucleotide phosphodiesterases (PDEs),

\section{AFFILIATIONS}

*Medical Research Council Unit for Inflammation and Immunity, Dept of Immunology, Faculty of Health

Sciences, University of Pretoria, and Tshwane Academic Division of the National Health Laboratory Service, Pretoria, and

\#Division of Pulmonology, Dept of Medicine, Charlotte Maxeke Johannesburg Academic Hospital and Faculty of Health Sciences, University of the Witwatersrand, Johannesburg, South Africa.

\section{CORRESPONDENCE}

R. Anderson

Dept Immunology

PO Box 2034

Pretoria

0001

South Africa

E-mail: ronald.anderson@up.ac.za

Received:

Oct 062009

Accepted after revision:

April 052010

First published online:

April 222010 
resulting in cAMP-dependent inhibition of neutrophil proinflammatory activity [9]. Although untested, it is plausible that the combination of formoterol and montelukast may exert augmentative, cAMP-dependent anti-inflammatory activity through the respective interactions of these agents with $\beta_{2^{-}}$ adrenoreceptors and PDEs, especially PDE4 [13].

In the current study, we have investigated the effects of formoterol and montelukast, individually and in combination, on several pro-inflammatory activities of activated neutrophils in relation to alterations in cAMP and $\mathrm{Ca}^{2+}$ handling by the cells, which is the primary focus of the study. In a limited series of experiments we have also included dexamethasone and salbutamol for comparison.

\section{MATERIALS AND METHODS}

\section{Chemicals and reagents}

Formoterol fumarate dehydrate and dexamethasone were purchased from Sigma-Aldrich (Pty) Ltd (Johannesburg, South Africa) and montelukast provided by Merck Research Laboratories (Rahway, NJ, USA), while salbutamol and rolipram were provided by GlaxoSmithKline Plc (Stockley Park, UK). With the exception of salbutamol (water soluble) all agents were dissolved to a stock concentration of $10 \mathrm{mM}$ in dimethyl sulphoxide (DMSO) and used at final concentrations of 1 and $10 \mathrm{nM}$ (formoterol), $2 \mu \mathrm{M}$ (montelukast), $100 \mathrm{nM}$ (salbutamol), $1 \mu \mathrm{M}$ (dexamethasone) and $1 \mu \mathrm{M}$ (rolipram) in the various assays of neutrophil function described below. The final concentrations of DMSO in each assay ranged from $0.1-$ $0.2 \%$ and appropriate solvent controls were included with each experimental system.

The concentrations of montelukast used in the current study (1-2 $\mu \mathrm{M})$ closely approximate peak serum levels of $\sim 1 \mu \mathrm{M}$ attained during chemotherapy with this agent [14]. The concentration of formoterol in the airways is, however, more difficult to ascertain. Assuming a maximum single dose of $24 \mu \mathrm{g}$ and lung deposition of $18.6 \%$, the total amount of formoterol reaching the airways would be $\sim 4.5 \mu \mathrm{g}$ [15]. Given a tidal volume of $500 \mathrm{~mL}$, this would equate to a local concentration of $9 \mathrm{ng} \cdot \mathrm{mL}^{-1}$, which is equivalent to $11 \mathrm{nM}$, close to the highest concentration of $10 \mathrm{nM}$ used in the current study. Unless indicated, all other chemicals and reagents were purchased from Sigma-Aldrich.

The chemoattractant, $N$-formyl-L-methionyl-L-leucyl-L-phenylalanine (fMLP; $1 \mu \mathrm{M}$ final), in combination with cytochalasin B (CB; $3 \mu \mathrm{M}$ final) was used to activate the neutrophils. This relatively strong activator (fMLP/CB) was used because of the anti-inflammatory potency of formoterol and montelukast. An additional chemoattractant, platelet-activating factor (PAF; $200 \mathrm{nM}$ ) was used in an additional, limited series of experiments.

\section{Preparation of neutrophils}

The study was approved by the Faculty of Health Sciences research ethics committee of the University of Pretoria, Pretoria, South Africa and prior informed consent was obtained from all blood donors. These cells were isolated from heparinised venous blood (5 units of preservative-free heparin per $\mathrm{mL}$ of blood) from nonsmoking healthy adult volunteers. Each subject completed a detailed health questionnaire and underwent a health check (including measurement of blood pressure) by an experienced, qualified nursing sister prior to venepuncture. Neutrophils were separated from mononuclear leucocytes by centrifugation on Histopaque-1077 (Sigma Diagnostics, St Louis, MO, USA) cushions at $400 \times g$ for $25 \mathrm{~min}$ at room temperature. The resultant pellets were suspended in PBS (0.15 M, pH 7.4) and sedimented with $3 \%$ gelatin to remove most of the erythrocytes. Following centrifugation $\left(280 \times g\right.$ at $10^{\circ} \mathrm{C}$ for $10 \mathrm{~min}$ ), residual erythrocytes were removed by selective lysis with $0.83 \%$ ammonium chloride at $4{ }^{\circ} \mathrm{C}$ for $10 \mathrm{~min}$. The neutrophils, which were routinely of high purity $(>90 \%)$ and viability $(>95 \%)$, were resuspended to $1 \times 10^{7}$ cells $\cdot \mathrm{mL}^{-1}$ in PBS and held on ice until used.

\section{Superoxide generation}

This was measured using a lucigenin (bis- $N$-methylacridinium nitrate)-enhanced chemiluminescence (LECL) procedure. Briefly, neutrophils $\left(10^{6}\right.$ cells) were pre-incubated without and with montelukast $(2 \mu \mathrm{M})$ in $900 \mu \mathrm{L}$ Hanks' balanced salt solution (HBSS, pH 7.4, indicator-free; Highveld Biological (Pty) Ltd, Johannesburg, South Africa) containing $0.2 \mathrm{mM}$ lucigenin. Following pre-incubation, formoterol (1 or $10 \mathrm{nM}$ ) was added to the cells (or an equal volume of solvent to control systems) followed $20 \mathrm{~s}$ later by $\mathrm{fMLP} / \mathrm{CB}$, and LECL responses recorded using a Lumac Biocounter (model 2010; Lumac Systems Inc., Titusville, FL, USA). The final volume in each vial was $1 \mathrm{~mL}$, and the results, which are expressed in relative light units (rlu), are the peak values for fMLP/CB-activated systems that were reached $40-50 \mathrm{~s}$ after the addition of the activator. There were four systems in each experiment: 1) neutrophils only (control); 2) neutrophils + formoterol; 3) neutrophils + montelukast; and 4) neutrophils + montelukast + formoterol.

\section{Elastase release}

Neutrophil degranulation was measured according to the extent of release of the primary granule enzyme, elastase. Neutrophils were incubated at a concentration of $2 \times 10^{6} \mathrm{~mL}^{-1}$ in HBSS without and with montelukast $(2 \mu \mathrm{M})$ for $10 \mathrm{~min}$ at $37^{\circ} \mathrm{C}$ followed by addition of formoterol (1 or $\left.10 \mathrm{nM}\right)$ or solvent control to the relevant systems and $20 \mathrm{~s}$ later by fMLP/ $\mathrm{CB}$, and the tubes then incubated for $15 \mathrm{~min}$ at $37^{\circ} \mathrm{C}$. The tubes were then transferred to an ice bath, followed by centrifugation at $400 \times g$ for $5 \mathrm{~min}$ to pellet the cells, and the supernatants were decanted and assayed for elastase using a micromodification of a standard colorimetric procedure. Briefly, $125 \mu \mathrm{L}$ of supernatant were added to the elastase substrate, $N$-succinyl-Lalanyl-L-alanine- $p$-nitroanilide $\left(3 \mathrm{mmol} \cdot \mathrm{L}^{-1}\right.$ in $\left.\mathrm{DMSO}\right)$ in $0.05 \mathrm{M}$ Tris- $\mathrm{HCl}$ ( $\mathrm{pH} 8.0$ ), and elastase activity was monitored spectrophotometrically at a wavelength of $405 \mathrm{~nm}$. The effects of the corticosteroid dexamethasone $(1 \mu \mathrm{M})$ on elastase release by $\mathrm{fMLP} / \mathrm{CB}$-activated neutrophils were also investigated in a more limited series of experiments. The corticosteroid was present with the cells during the $10 \mathrm{~min}$ pre-incubation period.

\section{CR3 expression}

Expression of CR3 on resting and fMLP/CB-activated neutrophils in the absence or presence of formoterol $(10 \mathrm{nM})$ and montelukast $(2 \mu \mathrm{M})$, individually and in combination, was measured flow cytometrically. Neutrophils $\left(1 \times 10^{6} \mathrm{~mL}^{-1}\right.$ final $)$ were incubated in HBSS with and without montelukast for $10 \mathrm{~min}$ at $37^{\circ} \mathrm{C}$ followed by the addition of formoterol or solvent 
control to the relevant systems and $20 \mathrm{~s}$ later by fMLP/CB. The tubes were incubated for $1 \mathrm{~min}$ and the reaction stopped by dilution of the cells in ice-cold medium. Phycoerythrin-labelled monoclonal antibody to CD11b (Beckman Coulter, Miami, FL, USA) was added in a $10 \mu \mathrm{L}$ volume to $1 \mathrm{~mL}$ of cell suspension and CR3 expression analysed using an Epics Altra Flow Cytometer equipped with a water-cooled Enterprise Laser (Beckman Coulter) and the results expressed as mean fluorescence intensity.

\section{Spectrofluorimetric measurement of cytosolic $\mathrm{Ca}^{2+}$}

Fura-2 acetoxymethyl ester (fura-2AM) was used as the fluorescent, $\mathrm{Ca}^{2+}$-sensitive indicator for these experiments [16]. Neutrophils $\left(1 \times 10^{7} \mathrm{~mL}^{-1}\right)$ were incubated with fura2AM $(2 \mu \mathrm{M})$ for $30 \mathrm{~min}$ at $37^{\circ} \mathrm{C}$ in PBS, washed and resuspended in HBSS. The fura-2-loaded cells $\left(2 \times 10^{6} \mathrm{~mL}^{-1}\right)$ were then pre-incubated for $10 \mathrm{~min}$ at $37^{\circ} \mathrm{C}$ without and with montelukast $(2 \mu \mathrm{M})$ after which they were transferred to disposable reaction cuvettes which were maintained at $37^{\circ} \mathrm{C}$ in a Hitachi 650 10S fluorescence spectrophotometer with excitation and emission wavelengths set at 340 and $500 \mathrm{~nm}$, respectively. After a stable baseline was obtained ( $\pm 1 \mathrm{~min})$, formoterol (10 $\mathrm{nM}$ only) or solvent control was added to the relevant systems followed $20 \mathrm{~s}$ later by $\mathrm{fMLP} / \mathrm{CB}$, and alterations in fluorescence intensity monitored over a 5$10 \mathrm{~min}$ time course. Cytosolic $\mathrm{Ca}^{2+}$ concentrations were calculated as described previously [16]. In a more limited series of experiments, the following were also investigated: 1) the effects of the short-acting $\beta_{2}$-receptor agonist, salbutamol (100 nM final, predetermined in preliminary experiments) without and with montelukast $(1 \mu \mathrm{M})$ on PAF $(200 \mathrm{nM})$ activated increases in cytosolic $\mathrm{Ca}^{2+}$ concentrations in neutrophils; 2) the effects of formoterol $(10 \mathrm{nM})$ alone or in combination with the prototype $\mathrm{PDE}_{4}$ inhibitor rolipram (fixed, final concentration of $1 \mu \mathrm{M}$ ); and 3) the effects of dexamethasone $(1 \mu \mathrm{M})$ on fMLP/CB-activated $\mathrm{Ca}^{2+}$ fluxes in neutrophils. Montelukast, rolipram and dexamethasone were present with the cells during the $10 \mathrm{~min}$ pre-incubation period, while salbutamol or formoterol were added $20 \mathrm{~s}$ prior to the activation of the cells.

\section{Measurement of leukotriene $B_{4}$ and cAMP}

Competitive binding immunoassay procedures (CorrelateEIA $^{\text {TM }}$; Assay Designs Inc., Ann Arbor, MI, USA) were used to measure leukotriene (LT)B $B_{4}$ in the supernatants of fMLP/ CB-activated neutrophils, while cAMP was assayed in the extracts of unstimulated cells in the absence and presence of formoterol and montelukast, individually and in combination. In the case of $\mathrm{LTB}_{4}$, neutrophils $\left(2 \times 10^{6} \mathrm{~mL}^{-1}\right)$ were preincubated for $10 \mathrm{~min}$ at $37^{\circ} \mathrm{C}$ in the absence and presence of montelukast $(2 \mu \mathrm{M})$, after which formoterol $(1$ or $10 \mathrm{nM})$ was added to the relevant systems, followed $20 \mathrm{~s}$ later by fMLP/ $\mathrm{CB}$. Incubation was terminated $3 \mathrm{~min}$ later by the addition of an equal volume of ice-cold HBSS to the tubes, which were then held in an ice bath prior to pelletting the cells by centrifugation. The cell-free supernatants were then diluted (1:8) and assayed for $\mathrm{LTB}_{4}$, with the results expressed as pg $\mathrm{LTB}_{4}$ per $10^{7}$ cells. As with the other assays of neutrophil proinflammatory activity, each experiment consisted of four systems: 1) neutrophils only (control); 2) neutrophils + formoterol; 3) neutrophils + montelukast; and 4) neutrophils
+ formoterol + montelukast. In a more limited series of experiments, the following were also investigated: 1) the effects of salbutamol (100 nM) without and with montelukast $(1 \mu \mathrm{M})$ on the production of $\mathrm{LTB}_{4}$ by PAF $(200 \mathrm{nM})$-activated neutrophils; and 2) the effects of dexamethasone $(1 \mu \mathrm{M})$ on the production of $\mathrm{LTB}_{4}$ by neutrophils activated with fMLP/CB.

In the case of cAMP, neutrophils $\left(2 \times 10^{6} \mathrm{~mL}^{-1}\right)$ were preincubated for $10 \mathrm{~min}$ at $37^{\circ} \mathrm{C}$ without or with montelukast $(2 \mu \mathrm{M})$, after which formoterol (10 nM only) was added to the relevant systems and the reactions terminated $20 \mathrm{~s}$ later by the addition of an equal volume of ice-cold HBSS to the tubes. Following centrifugation, the supernatants were discarded and cAMP extracted from the cell pellets by addition of $0.1 \mathrm{M} \mathrm{HCl}$ for $15 \mathrm{~min}$ followed by centrifugation to remove the cell debris and the supernatants decanted and assayed for cAMP. These results are expressed as pmol cAMP per $10^{7}$ cells.

\section{Statistical analysis}

With the exception of the results of the fura-2 fluorescence experiments, some of which are presented as representative traces, the results of each series of experiments are presented as the mean \pm SEM values, in which $n$ equals the number of different donors used in each series of experiments, with the number of replicates for each drug concentration and drug-free control system for each experiment shown in the figure legends. Levels of statistical significance were determined by comparing the absolute values for each drug-treated system with the corresponding values for the relevant drug-free control systems for each assay using repeated measures ANOVA with appropriate multiple comparisons post-test.

\section{RESULTS}

\section{Superoxide production, elastase release and $\mathrm{LTB}_{4}$}

These results for neutrophils activated with $\mathrm{FMLP} / \mathrm{CB}$ in the absence and presence of formoterol (1 and $10 \mathrm{nM})$ and montelukast $(2 \mu \mathrm{M})$ individually and in combination are shown in figure 1. Treatment of neutrophils with formoterol or montelukast significantly $(\mathrm{p}<0.05)$ attenuated the production of superoxide and $\mathrm{LTB}_{4}$ in particular, as well as the release of elastase, with the combination, especially in the case of $1 \mathrm{nM}$ formoterol, being significantly $(p<0.05)$ more effective in most cases, albeit additive rather than synergistic, than either of the individual agents. The exception was superoxide production, for which the effects of the combination differed only modestly from those of montelukast alone. The magnitude of inhibition of elastase release observed in the presence of montelukast, although statistically significant, was less than we had reported previously [9], probably because of the higher concentration of $\mathrm{CB}$ used in the current study.

Treatment of neutrophils with dexamethasone had minimal effects on the production of $\mathrm{LTB}_{4}$ and release of elastase from $\mathrm{fMLP} / \mathrm{CB}$-activated neutrophils. In the case of elastase the values for cells activated with $\mathrm{AMLP} / \mathrm{CB}$ in the absence and presence of dexamethasone were $950 \pm 15$ and $932 \pm 15$ milliunits elastase per $10^{7}$ cells, respectively. The corresponding values for $\mathrm{LTB}_{4}$ release were $7,213 \pm 110$ and $7,242 \pm 150 \mathrm{pg}$ $\mathrm{LTB}_{4}$ per $10^{7}$ cells (data from three separate experiments). The effects of salbutamol $(100 \mathrm{nM})$ and montelukast $(2 \mu \mathrm{M})$ individually and in combination on the release of $\mathrm{LTB}_{4}$ by PAF-activated neutrophils were also investigated. The results 

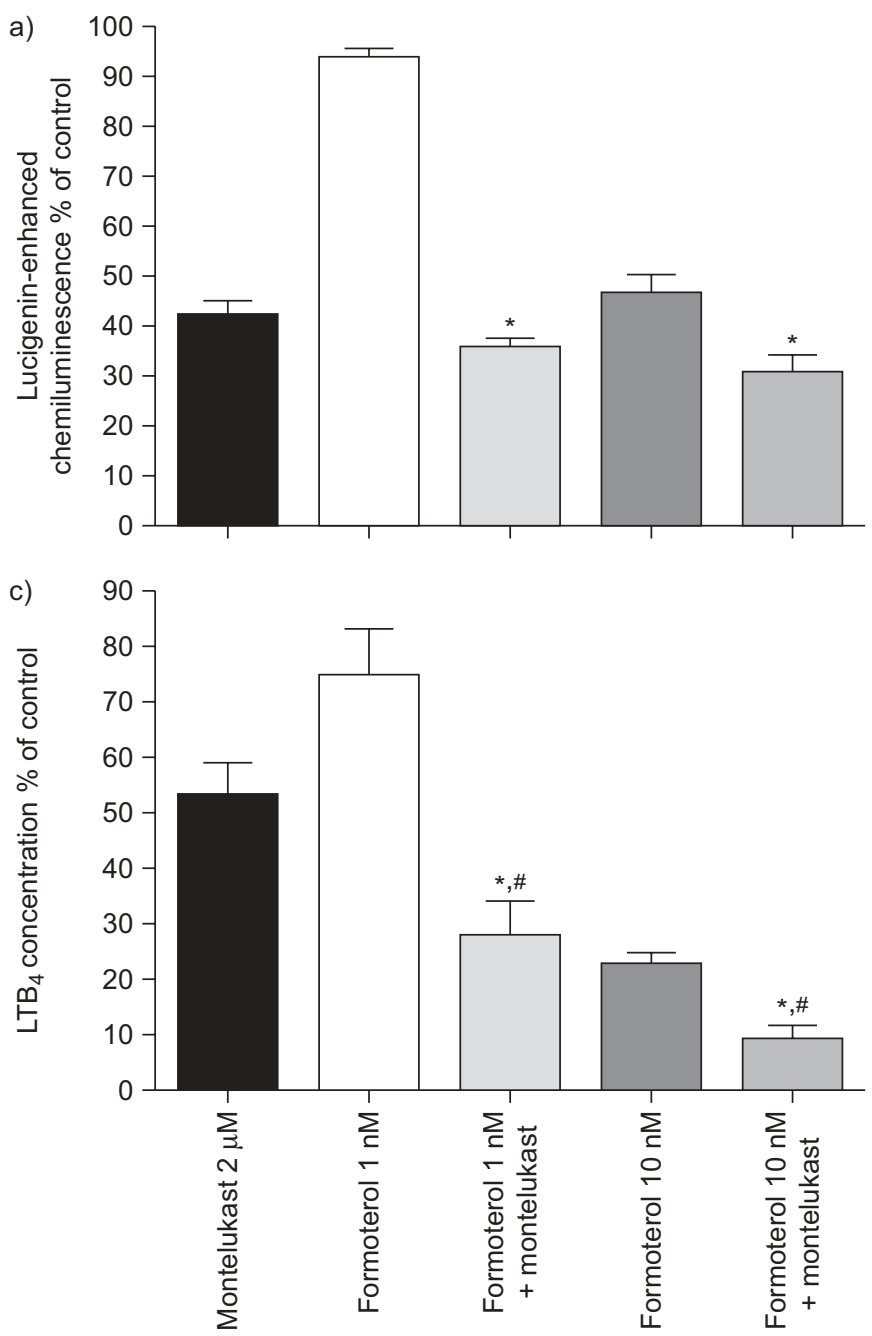

for unstimulated cells and for PAF-activated control cells and cells treated with salbutamol alone, montelukast alone, or the combination of these agents were $24 \pm 2,681 \pm 29,335 \pm 55$, $132 \pm 38$ and $65 \pm 17 \mathrm{pg} \mathrm{LTB} 4$ per $10^{7}$ cells, respectively $(\mathrm{p}<0.05$ for comparison of each drug-treated system with the control system and for the combination with the individual agents).

\section{CR3 expression}

The level of CR3 expression for resting neutrophils was $27 \pm 2$ mean fluorescence intensity. The corresponding levels of expression for control, fMLP/CB-activated cells and for the corresponding systems treated with formoterol (10 nM) only, montelukast $(2 \mu \mathrm{M})$ only, or the combination of these two agents were $92 \pm 2,71 \pm 3,81 \pm 2$ and $60 \pm 3$ mean fluorescence intensity respectively. The levels of CR3 expression were significantly less $(\mathrm{p}<0.05)$ than those of the control system for all three drug-treated systems, while the levels of CR3 expression in the system treated with both formoterol and montelukast was significantly less $(p<0.05)$ than that of the systems treated with the individual drugs.

\section{CAMP}

These results are shown in figure 2. Treatment of neutrophils with either formoterol $(10 \mathrm{nM})$ for $20 \mathrm{~s}$, or montelukast $(2 \mu \mathrm{M})$

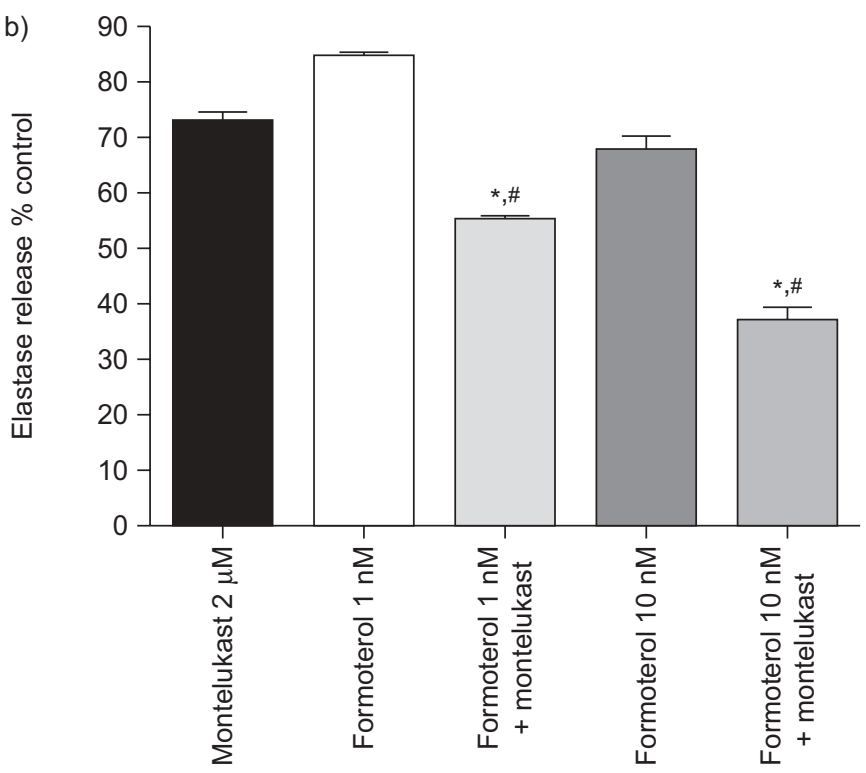

FIGURE 1. Effects of formoterol (1 and $10 \mathrm{nM})$ and montelukast $(2 \mu \mathrm{M})$ individually and in combination on a) the generation of superoxide, b) release of elastase, and c) production of leukotriene $(\mathrm{LT}) \mathrm{B}_{4}$ following activation of neutrophils with $N$-formyl-Lmethionyl-L-leucyl-L-phenylalanine (fMLP) in combination with cytochalasin $B(C B)$. For purposes of comparison, the data are presented as the mean \pm SEM $\%$ of control of a minimum of four different experiments using cells from four different donors. ${ }^{*}: p<0.05$ for comparison of the formoterol and montelukast combination with the system treated with montelukast alone; *: $p<0.05$ for comparison of the formoterol and montelukast combination with the system treated with formoterol alone. The absolute values for the responses of control (drug-free), unstimulated neutrophils for superoxide generation, release of elastase and production of $\mathrm{LTB}_{4}$ were $3,782 \pm 475$ rlu, $34 \pm 2$ milli-units enzyme per $10^{7}$ cells, and $37 \pm 5 \mathrm{pg} \mathrm{LTB} 4$ per $10^{7}$ cells, respectively; the corresponding values for the control systems activated with $\mathrm{fMLP} / \mathrm{CB}$ were $54,954 \pm 1,926 \mathrm{rlu}, 980 \pm 16$ milli-units enzyme per $10^{7}$ cells and $7,926 \pm 1,170$ pg LTB 4 per $10^{7}$ cells

resulted in significant $(\mathrm{p}<0.05)$ elevations in intracellular cAMP. Although higher than that observed with the individual agents, the increase in cAMP which resulted from treatment of the cells with the combination of montelukast and formoterol was not significantly different from that observed with the individual agents (fig. 2). We have previously reported that montelukast potentiates the increase in cAMP following exposure of neutrophils to salbutamol [9].

\section{Cytosolic calcium}

The alterations in cytosolic $\mathrm{Ca}^{2+}$ concentrations in $\mathrm{fMLP} / \mathrm{CB}-$ activated neutrophils were quantified using the strategy represented schematically in figure 3 . The results shown in figure 4 are traces from a representative experiment which depicts the alterations in cytosolic $\mathrm{Ca}^{2+}$ (fura-2 fluorescence) following activation of the cells with $\mathrm{MMLP} / \mathrm{CB}$ in the absence and presence of formoterol $(10 \mathrm{nM})$ and montelukast $(2 \mu \mathrm{M})$ individually and in combination. Activation of the cells with $\mathrm{fMLP} / \mathrm{CB}$ resulted in an abrupt increase in cytosolic $\mathrm{Ca}^{2+}$, with the peak response being sustained for 1-2 min, followed by a gradual subsidence which levelled off within 1-2 min reaching a sustained plateau at a level considerably higher than the preactivation, basal value for cytosolic $\mathrm{Ca}^{2+}$. Treatment of the cells with either montelukast $(2 \mu \mathrm{M})$ for $10 \mathrm{~min}$ or formoterol 


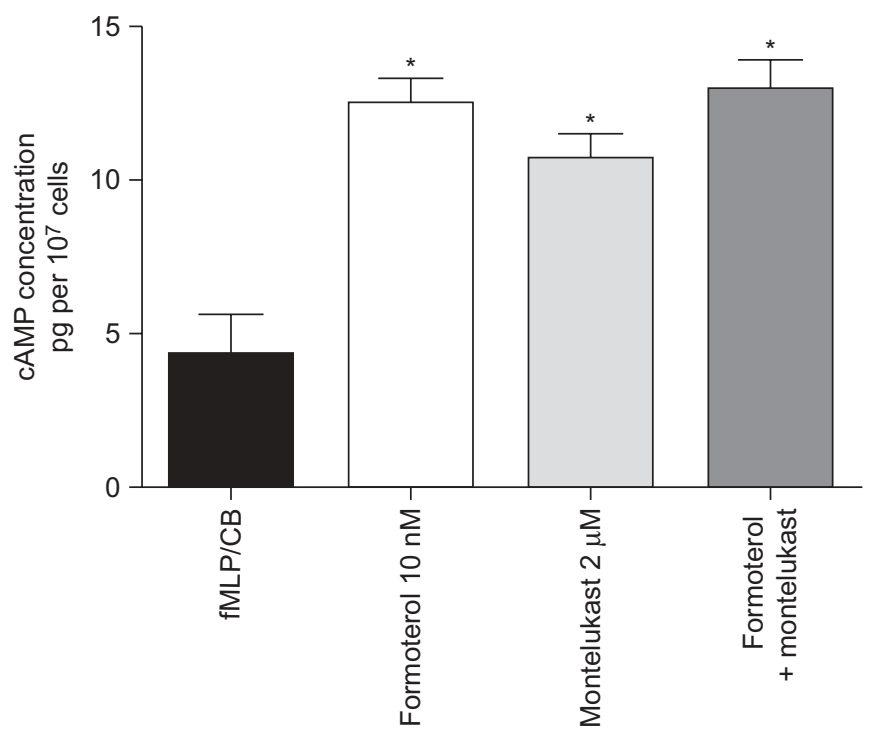

FIGURE 2. Effects of formoterol (10 nM) and montelukast $(2 \mu \mathrm{M})$ individually and in combination on neutrophil intracellular cyclic AMP (CAMP) levels. The results are expressed as the mean \pm SEM values (data from five different experiments using cells from five different donors). Exposure of the cells to either formoterol or montelukast was accompanied by significant $(p<0.05)$ elevations in CAMP, while the effects of the combination of agents, although greater, did not differ significantly from those of the individual agents. fMLP: $N$-formyl-L-methionyl-L-leucyl-L-phenyIalanine; CB: cytochalasin B. ${ }^{*}: p<0.05$.

$(10 \mathrm{nM})$ for $20 \mathrm{~s}$ prior to the addition of $\mathrm{fMLP} / \mathrm{CB}$ caused partial, but significant $(\mathrm{p}<0.05)$ attenuation of the peak, plateau cytosolic $\mathrm{Ca}^{2+}$ response, while accelerating the rate of decline, and decreasing the magnitude of the second, sustained plateau response. Again, the combination of montelukast and formoterol was found to be significantly $(p<0.05)$ more effective than the individual agents in promoting clearance of $\mathrm{Ca}^{2+}$ from the cytosol of fMLP/CB-activated neutrophils. These results are shown in table 1. Similar results (not shown) were obtained with the nonselective PDE inhibitor rolipram $(1 \mu \mathrm{M})$, in the presence or absence of formoterol $(10 \mathrm{nM})$.

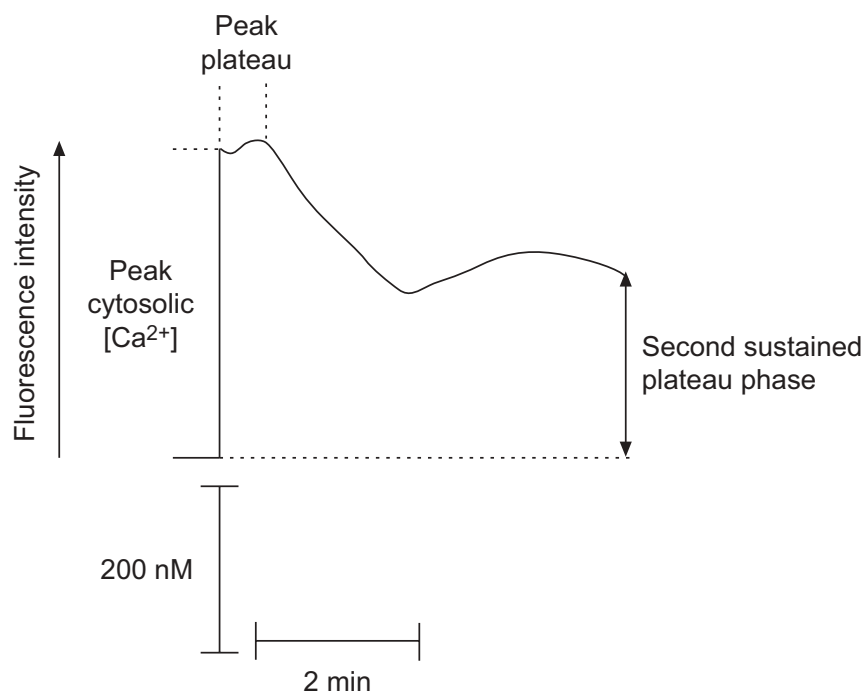

FIGURE 3. Schematic representation of the strategy used to measure the peak cytosolic $\mathrm{Ca}^{2+}$ concentration, duration of the peak plateau phase and magnitude of the second sustained increase in cytosolic $\mathrm{Ca}^{2+}$ concentration in activated neutrophils.

Addition of PAF $(200 \mu \mathrm{M})$ to neutrophils resulted in an abrupt increase in cytosolic $\mathrm{Ca}^{2+}$, which was followed by a sustained plateau phase and subsequent gradual decline towards basal levels. Pretreatment of neutrophils with salbutamol (100 nM) $20 \mathrm{~s}$ prior to addition of the stimulant did not alter the magnitude of the initial peak response, or the duration of the sustained plateau phase. However, the rate of decline in cytosolic $\mathrm{Ca}^{2+}$ concentrations was accelerated. In the presence of montelukast $(1 \mu \mathrm{M})$, the initial plateau phase was markedly attenuated and the rate of decline in cytosolic $\mathrm{Ca}^{2+}$ concentrations increased significantly. The combination of salbutamol and montelukast was more effective than either agent alone. These results are shown in figure 5 and table 2. Dexamethasone did not detectably alter $\mathrm{Ca}^{2+}$ fluxes in $\mathrm{fMLP} / \mathrm{CB}$-activated neutrophils (results not shown).
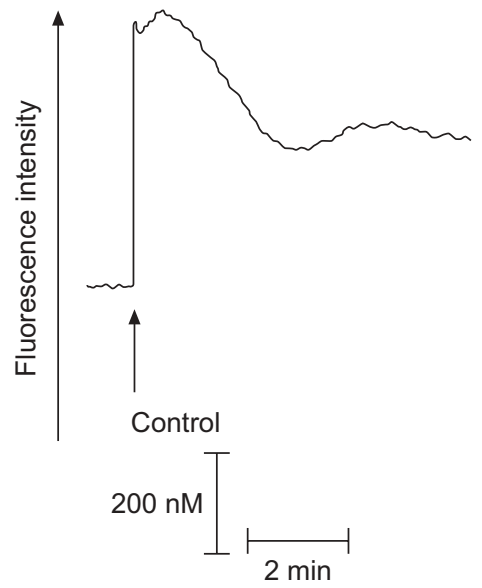

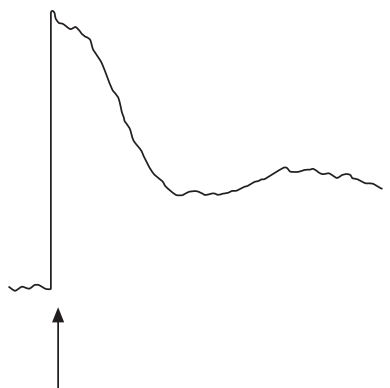

Formoterol $10 \mathrm{nM}$

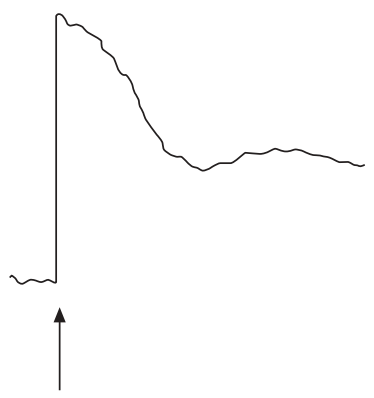

Montelukast $2 \mu \mathrm{M}$

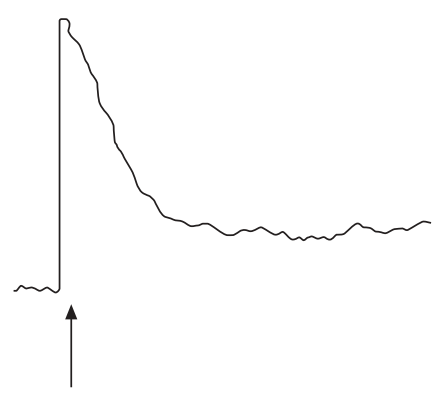

Formoterol + montelukast

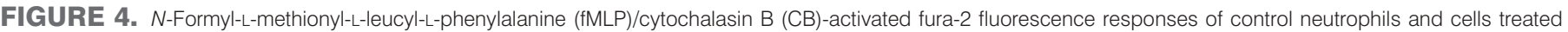

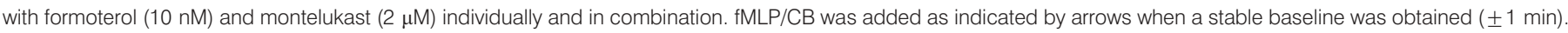
The traces are from an individual representative experiment (four in the series using cells from four different donors). 


\begin{tabular}{|c|c|c|c|c|}
\hline $\begin{array}{l}\text { TABLE } 1 \\
\text { System }\end{array}$ & \multicolumn{4}{|c|}{$\begin{array}{l}\text { Peak cytosolic } \mathrm{Ca}^{2+} \text { concentrations, duration of the plateau phase of the peak cytosolic } \mathrm{Ca}^{2+} \text { response, and area under } \\
\text { the curve measured in neutrophils activated with } \mathrm{N} \text {-formyl-L-methionyl-L-leucyl-L-phenylalanine (fMLP)/cytochalasin B } \\
\text { (CB) in the absence and presence of formoterol }(10 \mathrm{nM}) \text { and montelukast }(2 \mu \mathrm{M}) \text {, individually and in combination }\end{array}$} \\
\hline \multicolumn{2}{|c|}{ fMLP/CB only (control) } & $420 \pm 11$ & $1.3 \pm 0.1$ & $7.6 \pm 0.34$ \\
\hline \multicolumn{2}{|c|}{ fMLP/CB + montelukast } & $420 \pm 15$ & $0.9 \pm 0.1^{*}$ & $6.7 \pm 0.4^{\star}$ \\
\hline \multicolumn{2}{|c|}{ fMLP + formoterol + montelukast } & $415 \pm 13$ & $0.4 \pm 0.1^{\circ}$ & $5.4 \pm 0.4^{\bullet}$ \\
\hline
\end{tabular}

Data are presented as mean \pm SEM values from the results of four separate experiments using cells from four different donors. ${ }^{*}:$ measured 2 min after the addition of fMLP/CB. * : $p<0.05$ for comparison with the control system; ${ }^{\natural}: p<0.05$ for comparison of the combination with the individual agents.

\section{DISCUSSION}

Add-on therapy with montelukast has been reported to confer benefit on patients whose asthma is poorly controlled with inhaled corticosteroid monotherapy, or with the combination of a LABA and an inhaled steroid [17-22]. In this setting, it is believed that montelukast targets inflammatory mechanisms, specifically those orchestrated by cysteinyl leukotrienes and their receptors, thereby complementing the therapeutic actions of inhaled corticosteroids and $\beta_{2}$-agonists. However, this may not be the only mechanism by which add-on therapy with montelukast confers benefits on patients with poorly controlled asthma. The recently described effects of montelukast on PDEs [9] raise the possibility that this agent may act in concert with the other anti-asthma agents, particularly $\beta_{2^{-}}$ agonists, to augment cAMP-mediated anti-inflammatory activity and, possibly, bronchodilatory activity.

To test this hypothesis, we investigated the effects of formoterol (1 and $10 \mathrm{nM}$ ) and montelukast (1-2 $\mu \mathrm{M})$, individually and in combination, on the pro-inflammatory activities of human neutrophils. Treatment of neutrophils with either agent resulted in significant inhibition of the generation of

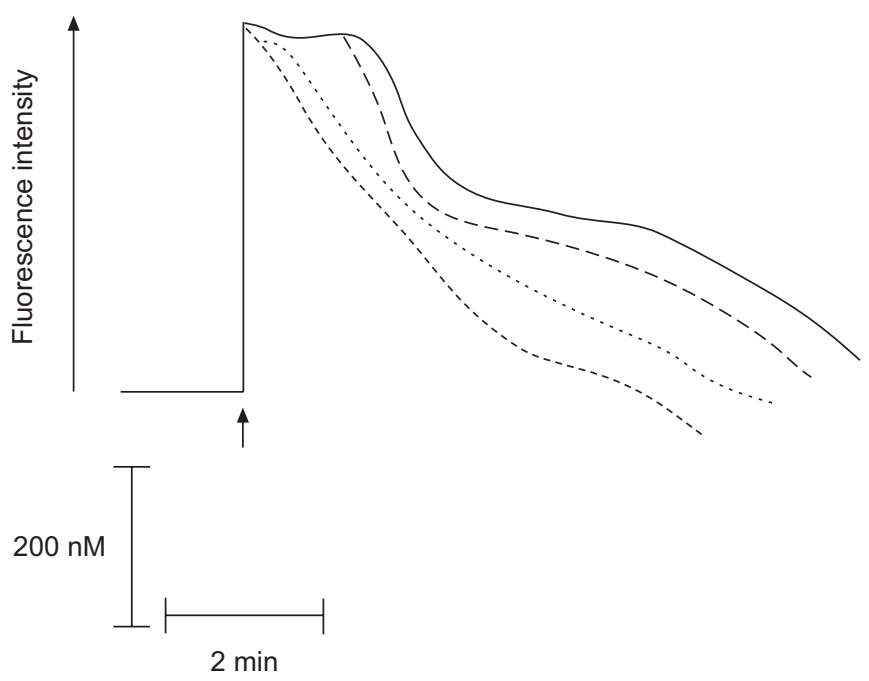

FIGURE 5. Effects of salbutamol (100 nM;-----) and montelukast $(1 \mu \mathrm{M} ; \cdots \cdots)$, alone and in combination (- - - - ), on the cytosolic $\mathrm{Ca}^{2+}$ concentrations of plateletactivating factor-activated (arrow) neutrophils. —_: controls. superoxide in particular, as well as expression of CR3 and release of elastase following activation of the cells with $\mathrm{AMLP} /$ $\mathrm{CB}$, with the combination being more effective than the individual agents, most notably in the case of CR3 expression and elastase release, the effects being additive as opposed to synergistic. In asthma, phagocyte-derived reactive oxygen species and elastase have been identified as possible mediators of bronchial hyperactivity and obstruction, and airway remodelling, respectively [23, 24], while interference with CR3 expression will restrict the migration of neutrophils into the airways. In the case of production of $\mathrm{LTB}_{4}$ by activated neutrophils, the individual agents were found to be extremely potent inhibitors of production of this eicosanoid with small, but nevertheless significant, augmentative effects observed with the combination of formoterol and montelukast. Notwithstanding the well-recognised involvement of cysteinyl leukotrienes in asthma, it is noteworthy that $\mathrm{LTB}_{4}$ also appears to play an important role in the pathogenesis of severe persistent asthma, as well as aspirin- and exercise-induced asthma, allergic rhinitis and atopic dermatitis [25]. Moreover, corticosteroids, which generally do not affect $\mathrm{LTB}_{4}$ production by immune and inflammatory cells, have been reported to upregulate the expression of the BLT1 receptor on corticosteroid-resistant cells such as neutrophils, monocytes and effector memory CD8+ T-cells [24-27]. In the current study, dexamethasone, an agent that does not elevate intracellular cAMP concentrations, had no detectable effects on either elastase or $\mathrm{LTB}_{4}$ release by activated neutrophils.

Although of limited relevance in the treatment of chronic asthma, or asthma in which inflammation is well-controlled, we also measured the effects of the short-acting $\beta_{2}$-agonist, salbutamol, on $\mathrm{LTB}_{4}$ production by neutrophils activated with PAF, a less potent stimulus than fMLP/CB. Salbutamol also inhibited the production of $\mathrm{LTB}_{4}$ by PAF-activated neutrophils, an effect that was augmented by inclusion of montelukast, probably by interactive cAMP-dependent mechanisms as described previously [9].

To probe the mechanism of formoterol/montelukast-mediated inhibition of the pro-inflammatory activity of neutrophils, we investigated the effects of these agents on alterations in cAMP and cytosolic $\mathrm{Ca}^{2+}$. Exposure of neutrophils to either formoterol or montelukast was accompanied by substantial increases in cAMP. In the case of montelukast, these were higher than 


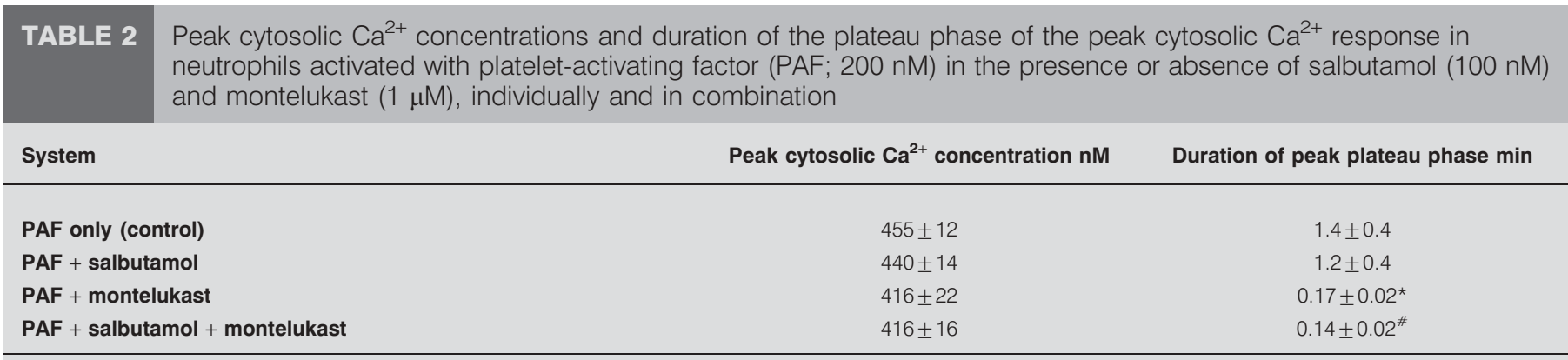

Data are presented as mean \pm SEM values from the results of five to 16 separate experiments using cells from four to six different donors. *: $p<0.05$ for comparison with the control system; ${ }^{\#}: \mathrm{p}<0.05$ for comparison of the combination with the individual agents.

we had reported previously [9]. This is most probably attributable to the longer exposure of the cells to the drug (10 $\mathrm{min}$ in the current study compared to $5 \mathrm{~min}$ in the previous study). Although the magnitude of the increase in cAMP observed with the combination was slightly higher than that observed with the individual agents, the difference did not achieve statistical significance. This may be due to the fact that we used a relatively brief exposure time (20 s) at which the effects of formoterol were maximal; longer exposure times may have revealed significant effects of the combination.

In neutrophils, the anti-inflammatory actions of agents that elevate intracellular cAMP are achieved primarily by activation of cAMP-dependent protein kinase (PKA). PKA in turn accelerates restoration of $\mathrm{Ca}^{2+}$ homeostasis and downregulation of pro-inflammatory activities following exposure of the cells to receptor-linked, $\mathrm{Ca}^{2+}$ mobilising stimuli by several mechanisms, including: phosphorylative inactivation of phospholipase C [28]; inactivation of inositol triphosphate receptors on intracellular $\mathrm{Ca}^{2+}$ stores [29]; upregulation of the $\mathrm{Ca}^{2+}$ sequestering/resequestering endo-membrane $\mathrm{Ca}^{2+}$-ATP [30]; and inhibition of p38 MAP kinase, resulting in interference with the activation of 5-lipoxygenase [31] and attenuation of an autocrine, $\mathrm{LTB}_{4}$-mediated secondary wave of $\mathrm{Ca}^{2+}$ uptake by the cells [32].

In the current study, formoterol and montelukast, in keeping with previous studies $[8,9]$, facilitated the clearance of $\mathrm{Ca}^{2+}$ from the cytosol of neutrophils activated with fMLP/CB without affecting mobilisation of the cation from intracellular stores. The two agents were most effective when used in combination. These observations are compatible with a mechanism whereby formoterol and montelukast, by targeting $\beta_{2}$-adrenoreceptors and PDEs, respectively, exert their individual and combined anti-inflammatory activities via cAMPdependent, accelerated restoration of $\mathrm{Ca}^{2+}$ homeostasis. This contention is supported by the following observations: 1) exposure of fMLP/CB-activated neutrophils to the type 4 PDE inhibitor rolipram, in combination with formoterol, resulted in decreases in cytosolic $\mathrm{Ca}^{2+}$ concentrations similar to those observed with montelukast and formoterol; and 2) montelukast potentiated the effects of salbutamol on clearance of $\mathrm{Ca}^{2+}$ from the cytosol of PAF-activated neutrophils. In keeping with its lack of effects on the release of elastase and $\mathrm{LTB}_{4}$, dexamethasone did not affect $\mathrm{Ca}^{2+}$ fluxes in fMLP/CBactivated neutrophils.
In conclusion, the results of the current study identify an interactive, cAMP-dependent mechanism by which formoterol and montelukast may support the anti-inflammatory actions of inhaled corticosteroids by targeting the intransigent neutrophil in patients with poorly controlled asthma.

\section{SUPPORT STATEMENT}

This study was supported, in part, by a research grant from the Investigator Initiated Studies Programme, Merck Research Laboratories, Rahway, NJ, USA.

\section{STATEMENT OF INTEREST}

Statements of interest for C.M. Gravett, C. Feldman and R. Anderson, and for the study itself, can be found at www.erj.ersjournals.com/site/ misc/statements.xhtml

\section{REFERENCES}

1 McFadden ER. Inhaled glucocorticoids and acute asthma: therapeutic breakthrough or non-specific effect? Am J Respir Crit Care Med 1998; 157: 677-678.

2 Van Weel C, Bateman ED, Bousquet J, et al. Asthma management pocket reference 2008. Allergy 2008; 63: 997-1004.

3 Johnson M. Molecular mechanisms of $\beta_{2}$-adrenergic receptor function, response and regulation. J Allergy Clin Immunol 2006; 117: 18-24.

4 Johnson M. Effects of $\beta_{2}$-agonists on resident and infiltrating inflammatory cells. J Allergy Clin Immunol 2002; 110: Suppl., S282-S290.

5 Lovén J, Svitacheva N, Jerre A, et al. Anti-inflammatory activity of $\beta_{2}$-agonists in primary lung epithelial cells is independent of glucocorticoid receptor. Eur Respir J 2007; 30: 848-856.

6 Barnes PJ. New molecular targets for the treatment of neutrophilic diseases. J Allergy Clin Immunol 2007; 119: 1055-1062.

7 Capra V, Ambrosio M, Riccioni G, et al. Cysteinyl-leukotriene receptor antagonists: present situation and future opportunities. Curr Med Chem 2006; 13: 3213-3216.

8 Tintinger GR, Theron AJ, Anderson R, et al. Comparison of the effects of selective and non-selective $\beta$-adrenergic agonists on the pro-inflammatory activities of human neutrophils in vitro. Inflammation 2000; 24: 239-249.

9 Anderson R, Theron AJ, Gravett CM, et al. Montelukast inhibits neutrophil pro-inflammatory activity by a cyclic AMP-dependent mechanism. Br J Pharmacol 2009; 156: 105-115.

10 Theron AJ, Gravett CM, Steel HC, et al. Leukotrienes $\mathrm{C}_{4}$ and $\mathrm{D}_{4}$ sensitize human neutrophils for hyperreactivity to chemoattractants. Inflamm Res 2009; 58: 263-268.

11 MacDowell AL, Peters SP. Neutrophils in asthma. Curr Allergy Asthma Rep 2007; 7: 464-468. 
12 Moore AR, Willoughby DA. The role of cAMP regulation in controlling inflammation. Clin Exp Immunol 1995; 101: 387-389.

13 Wang $\mathrm{P}, \mathrm{Wu} \mathrm{P}$, Ohleth $\mathrm{KM}$, et al. Phosphodiesterase 4B2 is the predominant phosphodiesterase species and undergoes differential regulation of gene expression in human monocytes and neutrophils. Mol Pharmacol 1999; 56: 170-174.

14 Knorr B, Holland S, Schwartz J, et al. Clinical pharmacology of montelukast. Clin Exp Allergy Rev 2001; 1: 254-260.

15 Farr SJ, Rowe AM, Rubsamen R, et al. Aerosol deposition in the human lung following administration from a microprocessor controlled pressurized metered dose inhaler. Thorax 1995; 50: 639-644.

16 Grynkiewicz G, Poenie M, Tsien RY. A new generation of $\mathrm{Ca}^{2+}$ indicators with greatly improved fluorescent properties. J Biol Chem 1985; 260: 3440-3450.

17 Dal Negro RW, Borderias L, Zhang Q, et al. Rates of asthma attacks in patients with previously inadequately controlled mild asthma treated in clinical practice with combination drug therapy: an exploratory post-hoc analysis. BMC Pulm Med 2009; 9: 10.

18 Currie GP, Lee DKC, Dempsey OJ, et al. A proof of concept study to evaluate putative benefits of montelukast in moderate persistent asthmatics. Br J Clin Pharmacol 2003; 55: 609-615.

19 Dempsey OJ, Wilson AM, Sims EJ, et al. Additive bronchoprotective effects with single doses of salmeterol and montelukast in asthmatic patients receiving inhaled corticosteroids. Chest 2000; 117: 950-953.

20 Dupont L, Potvin E, Korn D, et al. Improving asthma in patients suboptimally controlled on inhaled corticosteroids and long-acting $\beta_{2}$-agonists: addition of montelukast in an open-label pilot study. Curr Med Res Opin 2005; 21: 863-869.

21 Korn D, Van den Brande P, Potvin E, et al. Efficiency of add-on montelukast in patients with non-controlled asthma: a Belgian open-label study. Curr Med Res Opin 2009; 25: 489-497.

22 Keith PK, Koch C, Djandji M, et al. Montelukast as add-on therapy with inhaled corticosteroids and long-acting $\beta_{2}$-agonists in the management of patients diagnosed with asthma and concurrent allergic rhinitis (the RADAR trial). Can Respir J 2009; 16: 17-24.

23 Mak JC, Chan-Yeung MM. Reactive oxidant species in asthma. Curr Opin Pulm Med 2006; 12: 7-11.

24 Lee K-Y, Ho S-C, Lin H-C, et al. Neutrophil-derived elastase induces TGF- $\beta 1$ secretion in human airway smooth muscle. Am J Respir Cell Mol Biol 2006; 35: 407-414.

25 Ohnishi H, Miyahara N, Gelfand EW. The role of leukotriene $\mathrm{B}_{4}$ in allergic diseases. Allergol Int 2008; 57: 291-298.

26 Obinata H, Yokomizo T, Shimizu T, et al. Glucocorticoids upregulate leukotriene $\mathrm{B}_{4}$ receptor-1 expression during neutrophilic differentiation of HL-60 cells. Biochem Biophys Res Comm 2003; 309: 114-119.

27 Ohnishi H, Miyahara N, Dakhama A, et al. Corticosteroids enhance $\mathrm{CD}^{+} \mathrm{T}$ cell-mediated airway hyperresponsiveness and allergic inflammation by upregulating leukotriene $\mathrm{B}_{4}$ receptor 1 . J Allergy Clin Immunol 2008; 121: 864-871.

28 Ali H, Sozzani S, Fisher I, et al. Differential regulation of formyl peptide and platelet-activating factor receptors. Role of phospholipase $C \beta_{3}$ phosphorylation by protein kinase A. J Biol Chem 1998; 273: 11012-11016.

29 Bai Y, Sanderson MJ. Airway smooth muscle relaxation results from a reduction in the frequency of $\mathrm{Ca}^{2+}$ oscillations induced by a cAMP-mediated inhibition of the $\mathrm{IP}_{3}$ receptor. Respir Res 2006; 7: 34.

30 Anderson R, Visser SS, Ramafi G, et al. Accelerated resequestration of cytosolic calcium and suppression of the pro-inflammatory activities of human neutrophils by CGS 21680. Br J Pharmacol 2000; 130: 717-724.

31 Flamand N, Surette ME, Picard S, et al. Cyclic AMP-mediated inhibition of 5-lipoxygenase translocation and leukotriene biosynthesis in human neutrophils. Mol Pharmacol 2002; 62: 250-256.

32 Steel HC, Tintinger GR, Theron AJ, et al. Itraconazole-mediated inhibition of calcium entry into platelet-activating factor-stimulated human neutrophils is due to interference with production of leukotriene $\mathrm{B}_{4}$. Clin Exp Immunol 2007; 150: 144-150. 